\title{
Neuromonitoring in Spine Surgeries
}

\author{
Sohael M Khan ${ }^{1 *}$, Pradeep K Singh ${ }^{2}$, Kedar Phadke ${ }^{3}$, Shashank Jain ${ }^{4}$ and Pratik Patil ${ }^{4}$ \\ ${ }^{1}$ Assistant Professor and Consultant Spine Division, Department of Orthopaedics, Jawaharlal Nehru Medical College, India \\ ${ }^{2}$ Chief Spine Surgeon, Department of Spine Surgery, Dr H L Hiranandani Hospital, India \\ ${ }^{3}$ Chief Spine Surgeon, Department of Spine Surgery, Vadodara Institute of Orthopaedics, India \\ ${ }^{4} J u n i o r$ Resident, Department of Orthopaedics, Jawaharlal Nehru Medical College, India
}

Submission: July 04, 2017; Published: July 06, 2017

*Corresponding author: Sohael M Khan, Assistant Professor and Consultant Spine Division, Department of Orthopaedics, Jawaharlal Nehru

Medical College, Wardha, Maharashtra, India.

\section{Editorial}

In the earlier times of nascent spine surgery procedures, it was not possible to detect a neurological iatrogenic injury until the patient woke up from anesthesia. Now a day's majority of spinal surgeons use intraoperative neurophysiological monitoring during procedures at cord level especially in deformity correction. The aim behind this is to limit the risk of accidental injury to the neural structures. The purpose of IONM (Intra - operative Neuromonitoring) is to reduce the risk to the patient of iatrogenic damage to the Spinal Cord, and/or to provide functional guidance to the surgeon and anesthesiologist. Neuromonitoring is helpful in spine surgeries to detect injury in conditions where one would expect a neurological deterioration during positioning of the patient, during operative maneuvers and also when corrections are attempted during kyphosis or scoliosis surgeries. To accomplish these objectives, a subordinate of the surgical team with special expertise in neurophysiology obtains and co-interprets triggered and spontaneous electrophysiologic signals from the patient periodically or continuously throughout the course of the operation. In general, a trained neurophysiologist attaches a computer system to the patient using stimulating and recording electrodes.

There a various modalities of Neuromonitoring used. The most common ones are SSEP (somatosensory evoked potential), transcranial electric motor evoked potentials (TcMEPs), and electromyography (EMG). SSEP's help in evaluating dorsal column sensory pathway (TcMEPs) allow for a functional evaluation of the motor pathway, which includes the anterior or ventral corticospinal tracts of the spinal cord, plexus, and the peripheral nerve. Intermittently its applied transcranial electrical stimuli result in evoked potentials that can be recorded either directly from the spinal cord or indirectly from muscle. EMG is considered to evaluate nerve root integrity.

The primary objective is to identify and prevent the development of a new neurologic deficit or worsening of a preexisting neurologic injury in a patient who is undergoing surgery. The intention behind spinal cord monitoring is to prevent intraoperative injury that results in irreversible paraplegia or Tetraplegia. As the IONM is done in anaesthetized patient, IONP is used to determine neurological status of patient during surgery. It is done by evaluating \& recording the responses that are produced by the patient's nervous system to various types of stimulations that are given by the monitoring devise $\&$ thus monitoring the neural pathway.

As the patient is given anaesthesia, the Neuromonitoring is connected to the area of interest to be evaluated intra-op. These are connected to a computer devise where the signals are recorded time to time. These recording are started before the surgery and referred as baseline recordings and are continuously monitored throughout the surgery. Any substantial change or variations from the baseline values are used to determine whether significant neurological injury has occurred, The term significant change is used to refer to the degree of changes seen in the neurophysiologic recordings. Changes that are termed significant have been shown to correlate well with intraoperative injury to the nervous system. It is also possible that these changes, which are seen intra-operative, can arise from other technical errors like anaesthesia parameters or technical issues with the monitoring system. The main role of neurophysiologic monitoring team is to determine whether or not the significant changes noted intra-operatively are truly 
related to surgical procedure or they are due to technical error. The aim of the team is to inform the surgeon if there are any changes from the base line recording.

Key to the success of intraoperative neurophysiologic monitoring is a good understanding of the capabilities and limitations of the neurophysiologic tests being monitored. These limitations should be understood not only by the intraoperative neurophysiologist, but also by the anesthesiologist and surgeon. For seamless integration of intraoperative neuro- physiologic monitoring into the intraoperative team, it is imperative that a good established working relationship eventually develops between the intraoperative neurophysiology team, anesthesiologist, and surgeon. This relationship allows for rapid communication between teams and a quick resolution of issues, optimizing the benefits of intraoperative neuro- physiologic monitoring for the patient. Synchronization of efforts among the surgical, anesthetic, and Neuromonitoring teams allows for smooth progress of surgery and minimizes conflict.

Important considerations are choice of anesthetic technique and maintenance of blood pressure. Because inhalational agents tend to produce dose dependent changes in latency and amplitude of evoked potentials, their use should be avoided or minimized when Neuromonitoring is being used One of the first issues to tackle when planning for intra- operative neurophysiologic monitoring is to define the types of neurophysiologic tests to perform on a particular patient undergoing surgery. This decision is made based on an understanding of the type of surgery the patient is to undergo, the types of intraoperative injuries that may occur, and the mechanisms of how these injuries occur in surgery. By planning ahead with these issues in mind, the team can also attempt to anticipate the type of changes that might be expected to occur and the risky periods during surgery when these changes would likely occur. Ideally, the team would prospectively plan for interventions to reduce intraoperative neurologic injury [1].

\section{Conclusion}

However, in today's scenario Spine Surgery and Spinal cord injury are managed meticulously. Realizing the need of awareness of Spinal Cord the International Spinal Cord Society has decided to observe 5th September every year as SCI day [1]. Hence, the spine patients need more precise care and should have some knowledge regarding the same. Therefore, Neuromonitoring in spine surgery is becoming a need of the day. Neuromonitoring is an instrumental technique that provides information about iatrogenic neurologic injury. Precise understanding and high quality of medical practice of intra operative Neuromonitoring will be critical thus helping the surgeons to avoid injury to the cord and post - operative neurodeficit.

\section{References}

1. Chhabra HS, Batra S (2016) Spinal Cord Injury and its Impact on the patient, Family and the society. Int J Recent Surg Med Sci 2(1):1-4.

\section{Your next submission with Juniper Publishers will reach you the below assets}

- Quality Editorial service

- Swift Peer Review

- Reprints availability

- E-prints Service

- Manuscript Podcast for convenient understanding

- Global attainment for your research

- Manuscript accessibility in different formats

( Pdf, E-pub, Full Text, Audio)

- Unceasing customer service

Track the below URL for one-step submission https://juniperpublishers.com/online-submission.php 